Edu Komputika Journal

\title{
Perancangan Sistem Monitoring Suhu Ruangan Fermentasi Bawang Hitam Berbasis Mikrokontroler
}

\author{
Syaiful Rokhman, Dimas Wahyu Wibowo, Muhammad Aliyul Murtadlo ${ }^{\bowtie}$, Reffan \\ Pandu Amirulloh, Septian Caesar Floresko, Syahdanny Alhamda \\ Jurusan Teknologi Informasi, Program Studi Teknik Informatika, Politeknik Negeri Malang
}

\section{Info Artikel}

Sejarah Artikel:

Diterima: Desember 2019

Direvisi: Desember 2019

Disetujui: Desember 2019

\section{Keywords:}

Fermentation, Mobile

Application, Black Garlic,

DHT 11, Wemos D1 R2.

\begin{abstract}
Abstrak
Bawang putih termasuk tanaman yang sangat menguntungkan di dalam pengolahan, baik untuk dijadikan sebagai bumbu masakan maupun obat-obatan. Bawang putih juga dapat diolah dengan cara fermentasi yang akan menghasilkan bawang hitam. Proses fermentasi untuk menghasilkan bawang hitam melibatkan suhu dan kelembaban. Untuk dapat mengetahui nilai suhu dan kelembaban yang dihasilkan pada proses fermentasi maka digunakan suatu alat untuk dapat memonitoring suhu dan kelembaban. Pada alat ini monitoring sistem dilakukan oleh Mikrokontroler Wemos D1 R2 yang mempunyai input berbentuk sensor DHT11, sensor ini akan mendeteksi suhu dan kelembaban yang berada dalam alat fermentasi. Dari hasil informasi suhu dan kelembaban ruangan nantinya akan ditampilkan pada Aplikasi Mobile. Pada alat monitoring juga dilengkapi sebuah modul Wifi untuk mengirimkan data mengenai kondisi suhu dan kelembaban pada Aplikasi Mobile. Perancangan dan pengujian alat monitoring fermentasi ini menggunakan satu buah alat fermentasi yang didalamnya telah terdapat sensor DHT11. Pada pengujian akurasi sensor DHT11, diperoleh tingkat akurasi sebesar $99.30277175 \%$ untuk suhu pada alat fermentasi dan diperoleh tingkat akurasi sebesar $99.31489891 \%$ untuk kelembaban pada alat fermentasi.
\end{abstract}

\begin{abstract}
Garlic includes a very beneficial plant in processing, both to serve as a spice of cooking or medicine. Garlic can also be processed by fermentation that will produce the Black onion. The fermentation process to produce black onion involves the temperature and humidity in which the consistency must be thoroughly controlled. With the above problem can be done by design of fermentation tool to produce black onion by utilizing information technology. In this tool system control is done by a Wemos D1 R2 microcontroller that has an input in the form of a DHT11 sensor, this sensor will detect the temperature and humidity that are in the fermentation tool. From the results of temperature information and humidity will be displayed in the Mobile application. The Monitoring tool also includes a WiFi module to transmit data on the temperature and humidity conditions of the mobile application. The design and testing of this fermentation monitoring tool uses a fermentation device which has a DHT11 sensor in it. In testing the accuracy of the DHT11 sensor, an accuracy level of $99.30277175 \%$ for the temperature of the fermentation device was obtained and an accuracy level of $99.31489891 \%$ for the humidity of the fermentation device was obtained.
\end{abstract}




\section{PENDAHULUAN}

Bawang hitam adalah bawang putih yang dihangatkan pada suhu dan kelembaban tertentu sehingga menjadi hitam, lunak dan sedikit terasa asam[1]. Suhu atau temperatur adalah derajat panas dari aktivitas molekul dalam atmosfer. Suhu dikatakan sebagai derajat panas atau dingin yang diukur berdasarkan skala tertentu dengan menggunakan termometer [2]. Kelembaban udara adalah tingkat kebasahan udara karena dalam udara air selalu terkandung dalam uap air [3]. Sistem monitoring merupakan sistem yang didesain untuk bisa memberikan feedback ketika program sedang menjalankan fungsinya. Feedback dimaksudkan untuk memberikan informasi keadaan sistem pada saat itu. Sistem monitoring merupakan kumpulan prosedur dan program untuk mengkomputasi sistem informasi yang didesain untuk mencatat dan mentransmisikan data berdasarkan informasi yang diperoleh [4].

Dalam proses fermentasi bawang hitam, dibutuhkan suhu dan kelembaban yang tepat untuk mendapatkan produk hasil fermentasi yang maksimal. Hal tersebut jika dilakukan secara konvensional atau datang ke tempat monitoring secara langsung akan membutuhkan waktu dan energi yang banyak karena harus melihat informasi suhu dan kelembaban secara langsung pada alat fermentasi.

Untuk memaksimalkan waktu dan energi untuk mengukur suhu dan kelembaban, maka dibuatlah sebuah alat otomatis untuk memonitoring suhu dan kelembaban ruangan fermentasi bawang hitam yang terintegrasi dengan internet, sehingga pengguna dapat memperoleh informasi suhu dan kelembaban ruangan dari aplikasi yang telah dibangun untuk memonitoring suhu dan kelembaban ruangan fermentasi bawang hitam dimanapun.

\section{METODE PENELITIAN}

\section{Perancangan Alat dan Sistem}

Perancangan Alat/Sistem merupakan pembuatan rancangan alat atau sistem yang akan dibuat, berikut ini adalah diagram rancangan alat/sistem yang akan dibuat :

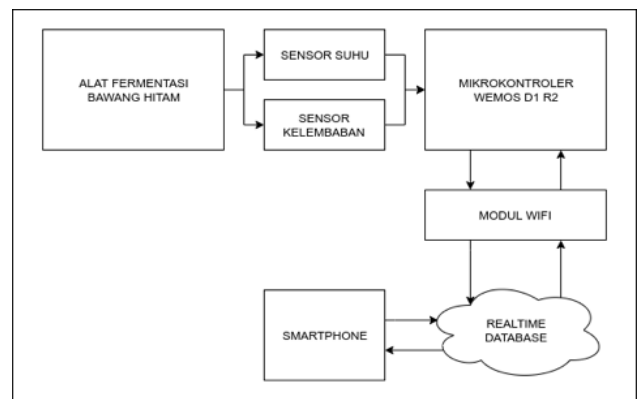

Gambar 1. Diagram sistem

Pada desain sistem di gambar 4, terdapat beberapa komponen yang digunakan dalam perancangan alat monitoring fermentasi. Berikut ini adalah komponen-komponen yang digunakan pada alat monitoring fermentasi:

1. Sensor Suhu dan Kelembaban

2. WeMos D1 R2

3. Modul WiFi

4. Realtime Database Firebase

5. Smartphone

Berikut ini adalah penjelasan alur diagram sistem yang telah dibuat:

1. Sensor suhu dan kelembaban DHT11 dipasang di alat fermentasi. Dari sensor suhu dan kelembaban ini akan didapatkan nilai berupa suhu dalam Celcius dan kelembaban dalam satuan persen. Sensor ini mengirim data ke mikrokontroler dengan menggunakan perantara kabel.

2. Mikrokontroler WeMos D1 R2 berfungsi untuk mengolah data dari sensor suhu dan kelembaban, kemudian mengirim data yang telah didapatkan ke realtime database Firebase dengan menggunakan modul wifi yang telah tersedia.

3. Pada realtime database Firebase akan dicatat id data, kelembaban, suhu, dan waktu update data. Pada realtime database Firebase ini juga dicatat pengaturan aplikasi. Realtime database Firebase ini berfungsi untuk menghubungkan alat monitoring fermentasi dengan smartphone.

Pada smartphone disediakan aplikasi untuk menampilkan data yang telah tersimpan di realtime database Firebase. Pada aplikasi yang telah dibuat juga dapat melakukan konfigurasi pada pengaturannya, pengaturan yang disediakan adalah pengaturan waktu update, suhu minimum dan maksimum serta kelembaban minimum dan maksimum. 


\section{Prosedur Penelitian}

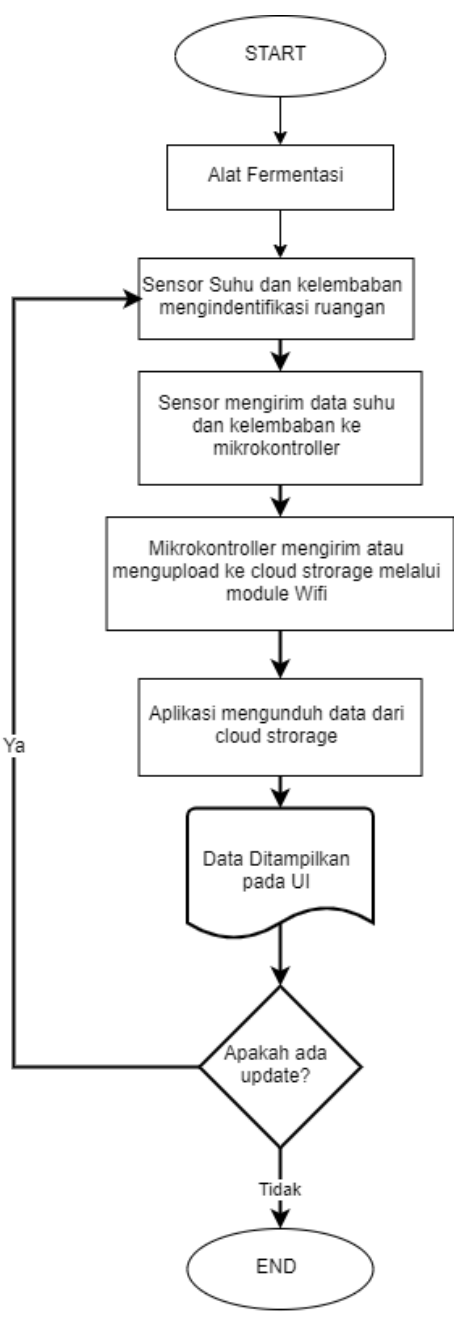

Gambar 2. Diagram alir cara kerja system pada alat fermentasi

Pada gambar 5 memperlihatkan dan menjelaskan flowchart aliran sistem secara keseluruhan pada penelitian ini. Langkah pertama, menghidupkan alat pemanas sebagai alat untuk fermentasi bawang hitam. Langkah selanjutnya, sensor suhu dan kelembaban di ruang fermentasi mengirimkan informasi suhu dan kelembaban ke Wemos D1 R2. Yang kemudian, data akan dikirim oleh mikrokontroler melalui wifi ke database. Selanjutnya, aplikasi mobile yang sudah dibuat akan mengambil data atau mengunduh data dari database. Berikutnya, pada aplikasi mobile akan menampilkan semua data yang diambil dari database sebagai dasar untuk monitoring suhu dan kelembaban pada ruangan.

Jika ada perubahan maka proses kembali ke sensor suhu dan kelembaban akan mengidentifikasi perubahan tersebut dan mengalir hingga update terbaru akan terlihat pada aplikasi mobile yang telah dibuat.

\section{HASIL DAN PEMBAHASAN}

\section{Hasil Perancangan Hardware}

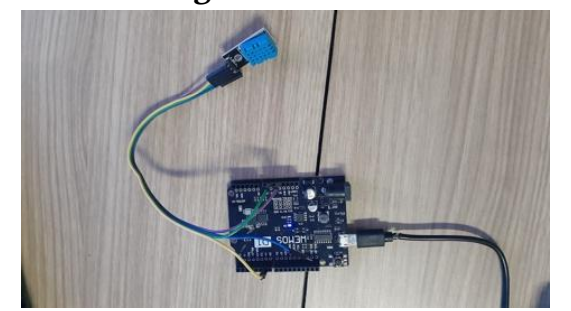

Gambar 3. Rancangan alat dengan sensor DHT11

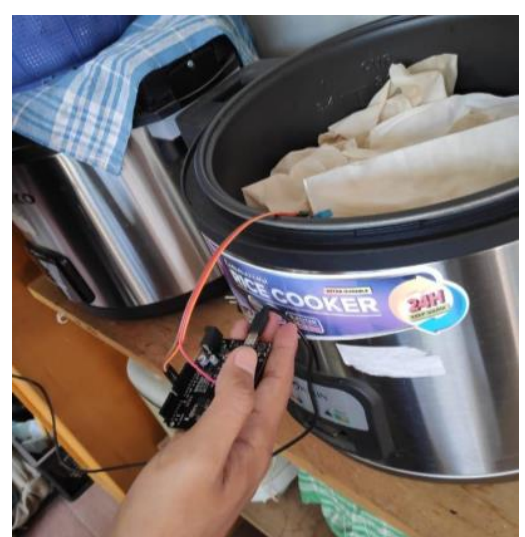

Gambar 4. Instalasi rancangan perangkat di alat fermentasi

\section{Hasil Desain Aplikasi Mobile}

Halaman Splash Screen
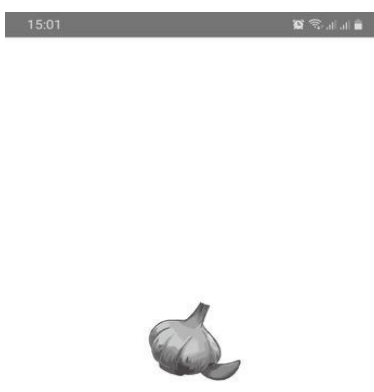

Bawang Hitam

Gambar 5. Halaman Splash Screen 
Halaman splash screen adalah halaman awal ketika aplikasi baru dimulai. Pada halaman ini ditampilkan logo dan nama obyek monitoring.

\section{Halaman Beranda}
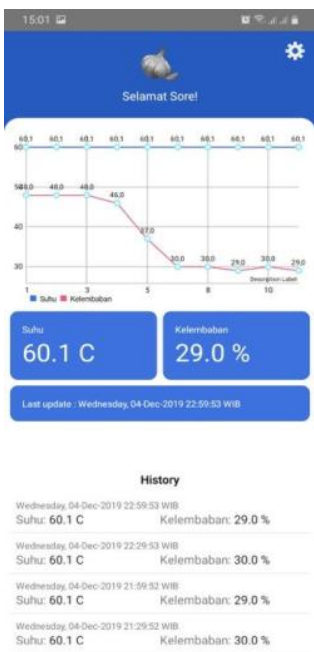

Gambar 6. Halaman Beranda

Halaman beranda berisi beberapa komponen yaitu grafik untuk menampilkan grafik perubahan pada 10 data terakhir, suhu untuk menampilkan nilai dari suhu terakhir, kelembaban untuk menampilkan nilai dari kelembaban terakhir, last update menampilkan waktu update terakhir, history untuk menampilkan riwayat 10 data terakhir, dan tombol pengaturan di pojok kanan atas untuk masuk ke halaman pengaturan.

\section{History}
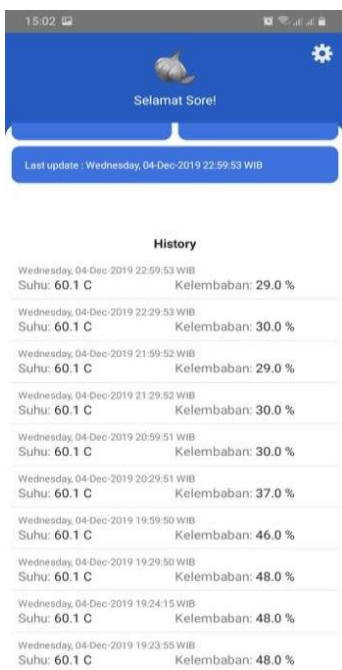

Gambar 7. History
Pada bagian ini menampilkan riwayat 10 data terakhir yang diambil oleh sensor suhu dan kelembaban. Data yang ditampilkan pada bagian ini adalah suhu, kelembaban dan waktu ketika suhu dan kelembaban diambil dan dimasukkan ke database.

\section{Halaman Pengaturan}

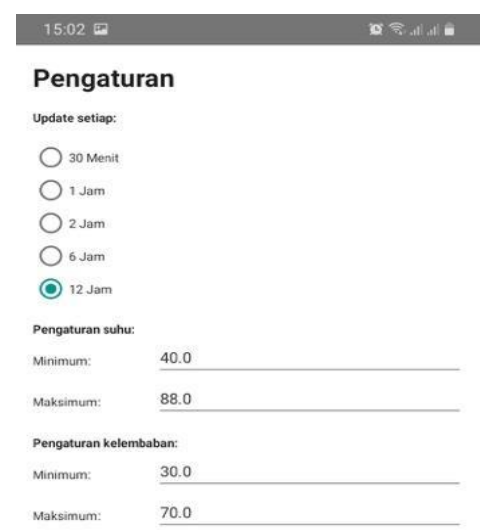

\section{SIMPAN}

Gambar 6. Halaman Pengaturan

Halaman pengaturan ini digunakan untuk mengatur berapa lama data akan di-update, mengatur suhu minimum dan maksimum serta mengatur kelembaban minimum dan maksimum.

\section{Hasil Pengujian}

Berikut ini adalah hasil pengujian yang telah dilakukan pada alat fermentasi bawang hitam, hasil dapat dilihat pada Tabel 1. 
Syaiful Rokhman, Dimas Wahyu Wibowo, Muhammad Aliyul Murtadlo, Reffan Pandu Amirulloh, Septian

Caesar Floresko, dan Syahdanny Alhamda / Edu Komputika 6 (2) (2019)

Tabel 1. Hasil Pengujian Alat Fermentasi Bawang Hitam

\begin{tabular}{|c|c|c|c|}
\hline \multicolumn{4}{|c|}{ Bawang Hitam } \\
\hline No & $\begin{array}{c}\text { Pembacaa } \\
\text { n Sensor } \\
\text { Kelembab } \\
\text { an } \\
\text { DHT11 }\end{array}$ & $\begin{array}{c}\text { Pembacaan } \\
\text { Sensor } \\
\text { Suhu } \\
\text { DHT11 }\end{array}$ & $\begin{array}{l}\text { Waktu } \\
\text { Pembacaan } \\
\text { Sensor }\end{array}$ \\
\hline 1 & 48.0 & 60.1 & $\begin{array}{l}\text { Saturday, 04-Jan- } \\
202019: 23: 55 \\
\text { WIB }\end{array}$ \\
\hline 2 & 48.0 & 60.1 & $\begin{array}{l}\text { Saturday, 04-Jan- } \\
202019: 24: 15 \\
\text { WIB }\end{array}$ \\
\hline 3 & 48.0 & 60.1 & $\begin{array}{l}\text { Saturday, 04-Jan- } \\
2020 \text { 19:29:50 } \\
\text { WIB }\end{array}$ \\
\hline 4 & 46.0 & 60.1 & $\begin{array}{l}\text { Saturday, 04-Jan- } \\
2020 \text { 19:59:50 } \\
\text { WIB }\end{array}$ \\
\hline 5 & 37.0 & 60.1 & $\begin{array}{l}\text { Saturday, 04-Jan- } \\
2020 \text { 20:29:51 } \\
\text { WIB }\end{array}$ \\
\hline 6 & 30.0 & 60.1 & $\begin{array}{l}\text { Saturday, 04-Jan- } \\
2020 \text { 20:59:51 } \\
\text { WIB }\end{array}$ \\
\hline 7 & 30.0 & 60.1 & $\begin{array}{l}\text { Saturday, 04-Jan- } \\
202021: 29: 52 \\
\text { WIB }\end{array}$ \\
\hline 8 & 29.0 & 60.1 & $\begin{array}{l}\text { Saturday, 04-Jan- } \\
2020 \text { 21:59:52 } \\
\text { WIB }\end{array}$ \\
\hline 9 & 30.0 & 60.1 & $\begin{array}{l}\text { Saturday, 04-Jan- } \\
2020 \text { 22:29:53 } \\
\text { WIB }\end{array}$ \\
\hline 10 & 29.0 & 60.1 & $\begin{array}{l}\text { Saturday, 04-Jan- } \\
2020 \text { 22:59:53 } \\
\text { WIB }\end{array}$ \\
\hline
\end{tabular}

Berikut ini adalah hasil pengujian yang telah dilakukan dengan menggunakan higrometer, dapat dilihat pada Tabel 2.
Tabel 2. Hasil Pengujian dengan Higrometer

\begin{tabular}{|c|c|c|c|}
\hline No & $\begin{array}{l}\text { Pembacaan } \\
\text { Kelembaban } \\
\text { menggunakan } \\
\text { Higrometer }\end{array}$ & $\begin{array}{l}\text { Pembacaan } \\
\text { Suhu } \\
\text { menggunakan } \\
\text { Higrometer }\end{array}$ & $\begin{array}{c}\text { Waktu } \\
\text { Pembacaan }\end{array}$ \\
\hline 1 & 46.3 & 58.8 & $\begin{array}{l}\text { Saturday, } \\
\text { 04-Jan-2020 } \\
\text { 19:23 WIB }\end{array}$ \\
\hline 2 & 46.4 & 58.8 & $\begin{array}{l}\text { Saturday, } \\
\text { 04-Jan-2020 } \\
\text { 19:24 WIB }\end{array}$ \\
\hline 3 & 46.9 & 59.1 & $\begin{array}{l}\text { Saturday, } \\
\text { 04-Jan-2020 } \\
\text { 19:29 WIB }\end{array}$ \\
\hline 4 & 44.7 & 59.3 & $\begin{array}{l}\text { Saturday, } \\
\text { 04-Jan-2020 } \\
\text { 19:59 WIB }\end{array}$ \\
\hline 5 & 36.7 & 59.9 & $\begin{array}{l}\text { Saturday, } \\
\text { 04-Jan-2020 } \\
\text { 20:29 WIB }\end{array}$ \\
\hline 6 & 30.3 & 60.4 & $\begin{array}{l}\text { Saturday, } \\
\text { 04-Jan-2020 } \\
\text { 20:59 WIB }\end{array}$ \\
\hline 7 & 30.5 & 60.3 & $\begin{array}{l}\text { Saturday, } \\
\text { 04-Jan-2020 } \\
\text { 21:29 WIB }\end{array}$ \\
\hline 8 & 29.8 & 59.9 & $\begin{array}{l}\text { Saturday, } \\
\text { 04-Jan-2020 } \\
\text { 21:59 WIB }\end{array}$ \\
\hline 9 & 29.9 & 60.0 & $\begin{array}{l}\text { Saturday, } \\
\text { 04-Jan-2020 } \\
\text { 22:29 WIB }\end{array}$ \\
\hline 10 & 29.4 & 60.4 & $\begin{array}{l}\text { Saturday, } \\
\text { 04-Jan-2020 } \\
\text { 22:59 WIB }\end{array}$ \\
\hline
\end{tabular}

Berikut ini adalah hasil penghitungan error suhu yang didapatkan dari sensor dan hygrometer, dapat dilihat pada Tabel 3. 
Syaiful Rokhman, Dimas Wahyu Wibowo, Muhammad Aliyul Murtadlo, Reffan Pandu Amirulloh, Septian

Caesar Floresko, dan Syahdanny Alhamda / Edu Komputika 6 (2) (2019)

Tabel 3. Hasil Penghitungan Error

\begin{tabular}{|c|c|c|c|}
\hline No & $\begin{array}{c}\text { Suhu } \\
\text { menggun } \\
\text { akan } \\
\text { Sensor } \\
\text { DHT11 }\end{array}$ & $\begin{array}{l}\text { Suhu } \\
\text { menggun } \\
\text { akan } \\
\text { Higrome } \\
\text { ter }\end{array}$ & Error (\%) \\
\hline 1 & 60.1 & 58.8 & 2.210884354 \\
\hline 2 & 60.1 & 58.8 & 2.210884354 \\
\hline 3 & 60.1 & 59.1 & 1.692047377 \\
\hline 4 & 60.1 & 59.3 & 1.349072513 \\
\hline 5 & 60.1 & 59.9 & 0.3338898164 \\
\hline 6 & 60.1 & 60.4 & -0.4966887417 \\
\hline 7 & 60.1 & 60.3 & -0.3316749585 \\
\hline 8 & 60.1 & 59.9 & 0.3338898164 \\
\hline 9 & 60.1 & 60.0 & 0.1666666667 \\
\hline 10 & 60.1 & 60.4 & -0.4966887417 \\
\hline \multicolumn{3}{|c|}{ Error rata-rata } & 0.6972282455 \\
\hline
\end{tabular}

Pada data Tabel 3 diatas terlihat bahwa ada perbedaan pembacaan suhu dari sensor DHT11 dan higrometer. Untuk menghitung persentase error dapat dihitung dengan rumus dibawah ini:

error suhu

$=\left|\frac{\text { nilai suhu DHT } 11-\text { nilai suhu higrometer }}{\text { nilai suhu higrometer }}\right| x 100 \%$

Dari hasil diketahui bahwa tingkat akurasi rata-rata adalah sebesar $99.30277175 \%$ dengan nilai error sebesar $0.6972282455 \%$.

Berikut ini adalah hasil penghitungan error kelembaban yang didapatkan dari sensor dan higrometer, dapat dilihat pada Tabel 4.
Tabel 4. Hasil Error Kelembaban

\begin{tabular}{|c|c|c|c|}
\hline No & $\begin{array}{l}\text { Kelembab } \\
\text { an } \\
\text { menggun } \\
\text { akan } \\
\text { Sensor } \\
\text { DHT11 }\end{array}$ & $\begin{array}{l}\text { Kelembab } \\
\text { an } \\
\text { menggun } \\
\text { akan } \\
\text { Higromet } \\
\text { er }\end{array}$ & Error (\%) \\
\hline 1 & 48.0 & 46.3 & 3.671706263 \\
\hline 2 & 48.0 & 46.4 & 3.448275862 \\
\hline 3 & 48.0 & 46.9 & 2.345415778 \\
\hline 4 & 46.0 & 44.7 & 2.908277405 \\
\hline 5 & 37.0 & 36.7 & 0.8174386921 \\
\hline 6 & 30.0 & 30.3 & -0.9900990099 \\
\hline 7 & 30.0 & 30.5 & -1.639344262 \\
\hline 8 & 29.0 & 29.8 & -2.684563758 \\
\hline 9 & 30.0 & 29.9 & 0.3344481605 \\
\hline 10 & 29.0 & 29.4 & -1.360544218 \\
\hline \multicolumn{3}{|c|}{ Error rata-rata } & 0.6851010913 \\
\hline
\end{tabular}

Pada data diatas terlihat bahwa ada perbedaan pembacaan kelembaban dari sensor DHT11 dan higrometer. Untuk menghitung persentase error dapat dihitung dengan rumus dibawah ini:

$$
\begin{aligned}
& \quad \begin{array}{l}
\text { error kelembaban } \\
=\left|\frac{\text { nilai kel.DHT11 - nilai kel. higrometer }}{\text { nilai kel. higrometer }}\right|
\end{array} \mid x 100 \% \\
& \text { Dari hasil diketahui bahwa tingkat }
\end{aligned}
$$
akurasi rata-rata adalah sebesar 99.31489891\% dengan nilai error sebesar 0.6851010913\%.

\section{SIMPULAN}

Berdasarkan hasil yang diperoleh dari pengujian, dapat disimpulkan bahwa suhu yang dihasilkan dan berhasil terbaca oleh sensor suhu adalah sekitar $60^{\circ} \mathrm{C}$ dan kelembabannya adalah sekitar 29\% hingga 50\%. Berdasarkan pengujian ini juga dapat disimpulkan bahwa sensor suhu dan kelembaban DHT11 masih dapat mengakomodasi suhu hingga lebih dari $60^{\circ} \mathrm{C}$. Tingkat akurasi yang didapatkan pada pengujian mencapai angka diatas $99.3 \%$ sehingga dapat disimpulkan bahwa pembacaan sensor ini stabil. 
Pada aplikasi monitoring suhu dapat membaca data yang dihasilkan oleh sensor yang telah diunggah di Realtime Database Firebase. Pada aplikasi juga terdapat fitur pengaturan untuk mengatur waktu update, mengatur batas minimum suhu dan kelembaban dan batas maksimum suhu dan kelembaban.

\section{SARAN}

1. Alat ini dapat dikembangkan di berbagai objek, tidak hanya digunakan untuk alat fermentasi bawang hitam.

2. Sensor suhu dan kelembaban dapat menggunakan sensor DHT22 yang lebih baik daripada sensor DHT11.

\section{UCAPAN TERIMA KASIH}

Ucapan terima kasih ditujukan kepada Dimas Wahyu Wibowo, ST., MT. selaku dosen mata kuliah Proyek 2. Ucapan terima kasih juga ditujukan kepada seluruh teman-teman yang mendukung pengembangan proyek ini.

\section{DAFTAR PUSTAKA}

[1] P. Bongiorno, Peter, B., Patrick, M.F., LoGiudice, "Potential health benefits of garlic (Allium Sativum): A narrative review," J. Complement. Integr. Med., 2008.

[2] Ance. Klimatologi Pengaruh Iklim Terhadap Tanah dan Tanaman, Bina Aksara, Jakarta, Asian Development Bank, 1986

[3] Abraham H.Oort. "Humidity Temperature Relationships In The Tropical Troposphere" Journal Climate, Vol.8, no 1, February, 1995

[4] Apri Siswanto, Rido Faldana, "Sistem Monitoring Rumah Berbasis Teknologi Cloud Computing" SESINDO, 2014.

[5] Platt, Sharle. Encyclopedia of Electronic Components Vol 1. America: O'Reilly Media.

[6] Mercy Corps. Design, Monitoring, and Evaluation Guidebook, 2005 